\title{
Caco-2 Cell Conditions Enabling Studies of Drug Absorption from Digestible Lipid-Based Formulations
}

\author{
Janneke Keemink' • Christel A. S. Bergström ' (D)
}

Received: 9 September 2017 / Accepted: 4 December 2017 / Published online: 26 February 2018

(C) The Author(s) 2018. This article is an open access publication

\begin{abstract}
Purpose To identify conditions allowing the use of cell-based models for studies of drug absorption during in vitro lipolysis of lipid-based formulations ( $\mathrm{LBFs}$ ).

Methods Caco-2 was selected as the cell-based model system. Monolayer integrity was evaluated by measuring mannitol permeability after incubating Caco-2 cells in the presence of components available during lipolysis. Pure excipients and formulations representing the lipid formulation classification system (LFCS) were evaluated before and after digestion. Porcine mucin was evaluated for its capacity to protect the cell monolayer.
\end{abstract}

Results Most undigested formulations were compatible with the cells (II-LC, IIIB-LC, and IV) although some needed mucin to protect against damaging effects (II-MC, IIIB-MC, ILC, and IIIA-LC). The pancreatic extract commonly used in digestion studies was incompatible with the cells but the Caco2 monolayers could withstand immobilized recombinant lipase. Upon digestion, long chain formulations caused more damage to Caco-2 cells than their undigested counterparts whereas medium chain formulations showed better tolerability after digestion.

Conclusions Most LBFs and components thereof (undigested and digested) are compatible with Caco-2 cells. Pancreatic enzyme is not tolerated by the cells but immobilized lipase can be used in combination with the cell monolayer. Mucin is beneficial for critical formulations and digestion products.

Electronic supplementary material The online version of this article (https://doi.org// 0. 1007/s | | 095-0 17-2327-8) contains supplementary material, which is available to authorized users.

Christel A. S. Bergström

christel.bergstrom@farmaci.uu.se

Department of Pharmacy, Uppsala Biomedical Center, Uppsala University, P.O. Box 580, SE-75I 23 Uppsala, Sweden
KEY WORDS Caco-2 cells · digestion · intestinal absorption · lipid-based formulation

\section{ABBREVIATIONS}

FaSSIF Fasted state simulated intestinal fluid

FFA Free fatty acid

HBSS Hank's Balanced Salt Solution

LBF Lipid-based formulation

LC Long-chain

LFCS Lipid formulation classification system

MC Medium-chain

$P_{\text {app }} \quad$ Apparent permeability

TEER Transepithelial electrical resistance

\section{INTRODUCTION}

Drug dissolution in gastrointestinal fluids is crucial for drug absorption. However, approximately $70 \%$ of new drug candidates show insufficient solubility to allow intestinal absorption (1). Therefore, formulation strategies have been developed to improve bioavailability. Of these, lipid-based formulations (LBFs) often provide a means to deliver highly lipophilic, poorly water-soluble compounds at concentrations high enough to support absorption. These formulations consist of various mixtures of oils, surfactants, and co-solvents and are classified according to their composition and physical characteristics in the lipid formulation classification system (LFCS) (2). Ultimately, LBFs are employed to keep the compounds in solution during their transit in the gastrointestinal tract and expose the absorptive site to drugs in a solubilized and/or supersaturated state.

However, upon oral administration, many of the formulation components undergo lipolysis which changes the solvation capacity of the medium keeping the drugs in solution. To simulate and study this digestion process in vivo, an in vitro 
lipolysis model is commonly used (3). This model allows estimation of (i) the extent of digestion, and (ii) the drug distribution between the three phases present in the gastrointestinal tract (i.e. oil, aqueous and solid/precipitated drug, phases). Unfortunately, these studies do not quantitatively predict the in vivo performance of the drugs. Rather, they provide rank order correlations, and it has been speculated that this is due to the absence of an absorptive sink (3-6). During in vitro lipolysis experiments, the drug is not transported away from the solution as would be the case if it was absorbed. This artifact drives higher supersaturation levels leading to precipitation in vitro that would not occur in viwo (7).

Previous work has addressed this issue. For example, biopharmaceutical modeling has been used to predict intestinal absorption using in vitro lipolysis data (8). Permeation studies have also been performed on intestinal tissue of rats with predigested LBFs (9). Both methods seem promising but do not capture the dynamics of the in vivo processes. Recently, Crum et al. suggested a new animal-based model coupling in situ intestinal perfusion in rats to the in vitro digestion of LBFs (10). This method provides real time observations, but is time consuming and, since it is animal-based, is mainly suited for mechanistic studies rather than routine screening.

The use of Caco-2 cells in-line with lipolysis would offer an easier and faster approach than in situ animal studies. Caco-2 cells are a human colon carcinoma cell line considered the gold standard for the assessment of oral drug absorption nowadays (11). Differentiated Caco-2 cells resemble the epithelium of the human intestine and allow the prediction of drug transport mediated by different pathways, e.g., passive and active transport via the para- and transcellular routes (12). However, digestion media used in lipolysis experiments have been shown to damage Caco-2 cells (13-15). The aim of this study was therefore to evaluate compatibility between Caco-2 cells and individual components present during in vitro digestions to identify conditions under which Caco-2 cells can be used in a new in vitro model that simultaneously investigates digestion and absorption of compounds present in LBFs. A protective layer of mucin was used to increase biorelevance and generate Caco-2 compatibility.

\section{MATERIALS AND METHODS}

\section{Materials}

All culture media and supplements were purchased from Invitrogen $\mathrm{AB}$ (Sweden). $\left[{ }^{14} \mathrm{C}\right]$-mannitol was purchased from PerkinElmer Sverige AB (Sweden); Novozym ${ }^{\circledR} 435$ (immobilized lipase) was obtained from Strem chemicals (France); and fasted state simulated intestinal fluid (FaSSIF) powder was obtained from biorelevant.com (UK). Trismaleate, $\mathrm{CaCl}_{2} \cdot 2 \mathrm{H}_{2} \mathrm{O}, \mathrm{NaCl}, \mathrm{NaOH}$, oleic acid, caprylic acid, mucin from porcine stomach type III, Soybean oil, Cremophor EL, Tween 85, PEG400, Carbitol, and porcine pancreatin extract $(8 \times$ USP specifications activity) were purchased from Sigma-Aldrich (USA). Maisine 35-1 was a kind gift from Gattefossé (France), and Captex 355 and Capmul MCM were kind gifts from Abitec (USA). Excipient details can be found in Table I.

\section{Lipid-Based Formulations}

Nine formulations were chosen to represent the four LFCS classes (16); these contained long-chain (LC) or mediumchain (MC) glycerides, surfactants, and co-solvents (Table II). The LBFs resemble formulations that were previously used to develop a standardized in vitro lipolysis method (17), and were herein selected to allow future comparisons between this standardized method and a potential digestion-absorption method to be developed based on the results obtained in the current study. Formulations were prepared as described previously (18). Briefly, excipients were pre-heated $\left(37^{\circ} \mathrm{C}\right.$, except for Maisine $\left.35-170^{\circ} \mathrm{C}\right)$ and weighed into glass vials according to predefined fractions $(\%$ $w / w$; Table II). Subsequently, vials were sealed, vortex mixed and placed on a shaker ( $300 \mathrm{rpm})$, at $37^{\circ} \mathrm{C}$ for $24 \mathrm{~h}$.

\section{Preparation of Pancreatic Extract}

Pancreatic extract was prepared by mixing $0.6 \mathrm{~g}$ pancreatin powder with $3 \mathrm{~mL}$ of lipolysis buffer containing $2 \mathrm{mM}$ Tris-

Table I Name and Composition of Excipients Used in the Investigated Lipid-Based Formulations

\begin{tabular}{|c|c|}
\hline Excipients & Composition \\
\hline \multicolumn{2}{|l|}{ Triglycerides } \\
\hline Soybean oil & $\begin{array}{l}\text { LC triglycerides: predominantly linoleic acid, linolenic } \\
\text { acid, oleic acid, stearic acid and palmitic acid }\end{array}$ \\
\hline Captex 355 & $\begin{array}{l}\text { MC triglycerides: predominantly glycerol tricaprylate } \\
\text { (C8)/caprate (C O })\end{array}$ \\
\hline \multicolumn{2}{|l|}{ Mixed glycerides } \\
\hline Maisine 35-I & $\begin{array}{l}\text { LC glycerides: } 33.5 \% \text { monoglyceride, } 50.9 \% \\
\text { diglyceride and I } 4.7 \% \text { triglyceride; predominantly } \\
\text { linoleic acid }(\mathrm{Cl} 8) \text { and oleic acid }(\mathrm{Cl} 8)\end{array}$ \\
\hline Capmul MCM & $\begin{array}{l}\text { MC glycerides: } 60.7 \% \text { monoglyceride, } 33.1 \% \\
\text { diglyceride and } 4.4 \% \text { triglyceride predominantly } \\
\text { caprylic acid (C8) and capric acid (C O) }\end{array}$ \\
\hline \multicolumn{2}{|l|}{ Surfactants } \\
\hline Cremophor EL & polyethoxylated castor oil (HLB |4-16) \\
\hline Tween 85 & polyoxyethylenesorbitan triolate (HLB I I) \\
\hline \multicolumn{2}{|l|}{ Cosolvents } \\
\hline PEG 400 & polyethylene glycol 400 \\
\hline Carbitol & diethylene glycol ethyl ether \\
\hline
\end{tabular}

Abbreviations: MC Medium-chain, LC Long-chain 
Table II Composition of Investigated LBFs, Representing All Classes of the Lipid Formulations Classification System

\begin{tabular}{|c|c|c|}
\hline Formulation & Composition (\% WM) & \\
\hline \multirow[t]{2}{*}{ I-MC } & $50 \%$ & Captex 355 \\
\hline & $50 \%$ & Capmul MCM \\
\hline \multirow[t]{3}{*}{ II-MC } & $32.5 \%$ & Captex 355 \\
\hline & $32.5 \%$ & Capmul MCM \\
\hline & $35 \%$ & Tween 85 \\
\hline \multirow[t]{3}{*}{ IIIA-MC } & $32.5 \%$ & Captex 355 \\
\hline & $32.5 \%$ & Capmul MCM \\
\hline & $35 \%$ & Cremophor EL \\
\hline \multirow[t]{4}{*}{ IIIB-MC } & $12.5 \%$ & Capmul MCM \\
\hline & $12.5 \%$ & Captex 355 \\
\hline & $25 \%$ & Carbitol \\
\hline & $50 \%$ & Cremophor EL \\
\hline \multirow[t]{2}{*}{ I-LC } & $50 \%$ & Soybean oil \\
\hline & $50 \%$ & Maisine 35-I \\
\hline \multirow[t]{3}{*}{ II-LC } & $32.5 \%$ & Soybean oil \\
\hline & $32.5 \%$ & Maisine 35-I \\
\hline & $35 \%$ & Tween 85 \\
\hline \multirow[t]{3}{*}{ IIIA-LC } & $32.5 \%$ & Soybean oil \\
\hline & $32.5 \%$ & Maisine 35-I \\
\hline & $35 \%$ & Cremophor EL \\
\hline \multirow[t]{3}{*}{ IIIB-LC } & $5 \%$ & Soybean oil \\
\hline & $45 \%$ & Tween 85 \\
\hline & $50 \%$ & Carbitol \\
\hline \multirow[t]{2}{*}{ IV } & $50 \%$ & Cremophor EL \\
\hline & $50 \%$ & Carbitol \\
\hline
\end{tabular}

I-IV denotes the type of lipid based formulation according to the lipid formulation classification system

Abbreviations: MC Medium-chain, LC Long-chain

maleate, $1.4 \mathrm{mM} \mathrm{CaCl}_{2}$, and $150 \mathrm{mM} \mathrm{NaCl}(\mathrm{pH}$ 6.5) followed by centrifugation for $15 \mathrm{~min}$ at $21,000 \mathrm{~g}$ and $5^{\circ} \mathrm{C}(17)$. Subsequently, the extract was diluted with digestion medium (lipolysis buffer supplemented with FaSSIF powder to obtain sodium taurocholate concentrations of $3.0 \mathrm{mM}$ and lecithin concentrations of $0.75 \mathrm{mM}$ ) to yield a lipase activity of 900 USP units (USPU/mL).

\section{In Vitro Lipolysis}

In vitro lipolysis was carried out as described previously with minor modifications (17). LBF was weighed directly into a thermostat-jacketed glass vessel (Metrohm, Switzerland) before digestion medium was added (final concentration of LBF was $2.5 \%(w / v))$. The formulation was dispersed for $10 \mathrm{~min}$ in the digestion medium using a propeller stirrer (450 rpm). During the dispersion phase, the $\mathrm{pH}$ was manually adjusted to $\mathrm{pH} 6.5 \pm 0.05$. The digestion was initiated by addition of lipase. A pH-stat (Metrohm 907 Titrando) was used to maintain a $\mathrm{pH}$ of 6.5 through titration with $0.2 \mathrm{M}$ (LC- and IV LBFs) or 0.6 M (MC-LBFs) NaOH. Samples were taken after $60 \mathrm{~min}$ of digestion and treated with $5 \mu \mathrm{L} / \mathrm{mL}$ lipase inhibitor (0.5 M 4-bromophenyl boronic acid in methanol) to inhibit further lipolysis.

Digestion was performed with pancreatic extract and immobilized lipase (Novozyme ${ }^{\circledR} 435$ ) in order to (i) compare the extent of digestion and (ii) select the concentration of immobilized lipase for performing in vitro lipolysis assays. Type IIIB-MC and IIIB-LC formulations were selected as representatives of the $\mathrm{MC}$ - and $\mathrm{LC}-\mathrm{LBF}$, respectively. Both formulations were digested according to the standardized protocol, using $900 \mathrm{USPU} / \mathrm{mL}$ of pancreatic extract, and with different concentrations of immobilized lipase (125, 250 or $750 \mathrm{PLU} / \mathrm{mL}$ ). The extent of digestion was determined by plotting the free fatty acid (FFA) release against time. The presence of pancreatic extract resulted in a more extensive digestion than the presence of immobilized lipase. Immobilized lipase concentrations above 125 PLU/mL resulted in a limited increase in FFA liberation (Fig. S1). However, higher concentrations (>125 PLU/mL) impeded stirring and homogenous sampling. Therefore, a concentration of $125 \mathrm{PLU} / \mathrm{mL}$ was selected to digest all LBFs for $60 \mathrm{~min}$.

\section{Cell Culture}

Caco-2 cells, obtained from American Type Culture Collection (Manassas, Virginia), were cultivated as described previously in an atmosphere of $90 \%$ air and $10 \% \mathrm{CO}_{2}(12)$. Briefly, Caco-2 cells (passage 95 to 105) were seeded on permeable polycarbonate filter supports $(0.45 \mu \mathrm{m}$ pore size, $12-$ mm diameter; Transwell Costar, Sigma-Aldrich) at a density of 44,000 cells $/ \mathrm{cm}^{2}$ in Dulbecco's modified Eagle's medium supplemented with $10 \%$ fetal calf serum, 1\% minimum essential medium nonessential amino acids, penicillin $(100 \mathrm{U} / \mathrm{mL})$, and streptomycin $(100 \mu \mathrm{g} / \mathrm{mL})$. Monolayers were used for experiments between day 21 and 26 after seeding.

\section{Compatibility Studies}

Caco-2 cells were incubated with components present during in vitro lipolysis. The conditions are presented in Table III. The selected concentrations represent 'worst-case' scenarios; while the in vivo situation is dynamic, these experiments were performed under static conditions with a high concentration of the test component for a relatively long time $(2 \mathrm{~h})$. Digestion medium was used as a control in all studies.

\section{TEER}

TEER measurements were used to identify cell monolayers that were suitable for transport studies. Before and after all 
Table III Conditions Tested for Compatibility with Caco-2 Cells

\begin{tabular}{|c|c|}
\hline Condition & \\
\hline Buffer & \\
\hline HBSS (pH 6.5) & Control \\
\hline Digestion buffer & Simulated intestinal fluid containing bile salts and phospholipids \\
\hline Excipients & \\
\hline $1.25 \%(w / v)$ & Highest concentration of a single excipient used during in vitro lipolysis (Table II) \\
\hline $0.625 \%(w / v)$ & Common concentration of single excipient used during in vitro lipolysis (Table II) \\
\hline $0.125 \%(w / v)$ & Common concentration of single excipient used during in vitro lipolysis (Table II) \\
\hline LBF & \\
\hline $2.5 \%(w / N)$ & Common LBF concentration used during in vitro lipolysis (I7), formulations describe in Table II \\
\hline Enzyme & \\
\hline Pancreatic enzyme (900 USPU/mL) & Common concentration of pancreatic enzyme added to in vitro lipolysis experiments (I7) \\
\hline Immobilized enzyme (I25 PLU/mL) & Concentration of immobilized enzyme required for digestion of LBF \\
\hline FFA & \\
\hline Caprylic acid (87 mM) & Highest concentration of MC FFA released in previous digestions (I7) \\
\hline Oleic acid (37.5 mM) & Highest concentration of LC FFA released in previous digestions (I7) \\
\hline Digested LBF & \\
\hline $\begin{array}{l}\text { LBF digested with immobilized enzyme } \\
\text { for } 60 \text { min }\end{array}$ & $\begin{array}{l}\text { Common concentration of LBF and time span of in vitro lipolysis experiments digested with an enzyme concentration } \\
\text { compatible with Caco-2 cells }\end{array}$ \\
\hline
\end{tabular}

permeability experiments, cells were washed with pre-warmed $\left(37^{\circ} \mathrm{C}\right)$ Hank's balanced salt solution (HBSS; 7.4) and equilibrated with HBSS for $15 \mathrm{~min}$. Subsequently, the confluence and integrity of the cell monolayers were assessed by measuring TEER. Only monolayers with initial TEER values greater than $250 \Omega . \mathrm{cm}^{2}$ were used for compatibility studies.

\section{$\left[{ }^{14} \mathrm{C}\right]$-mannitol Permeability}

The hydrophilic paracellular marker mannitol was used as a model compound to investigate the effect of the test components on the integrity of the Caco-2 monolayers. All solutions were pre-warmed to $37^{\circ} \mathrm{C}$. After, equilibrating cells with HBSS for $15 \mathrm{~min}$, the buffer was removed and the filters with the cell monolayers were transferred to wells containing $1.2 \mathrm{~mL}$ of fresh, pre-warmed HBSS (pH 7.4).

Transport studies were initiated by adding $400 \mu \mathrm{L}$ of digestion medium spiked with $\left[{ }^{14} \mathrm{C}\right]$ mannitol and components present during in vitro lipolysis (Table III) to the apical chamber. For components that were not compatible with the cells, the impact of mucin as a protective barrier was evaluated; mucin from porcine stomach type III (50 or $150 \mathrm{mg} / \mathrm{mL}$ ) was dissolved in digestion medium and $100-200 \mu \mathrm{L}$ was added to the monolayers. The monolayers were then incubated at $37^{\circ} \mathrm{C}$ for 10 min before initiating the transport experiment by adding the tests solutions containing $\left[{ }^{14} \mathrm{C}\right]$-mannitol (final volume $400 \mu \mathrm{L}$ in the apical chamber).
In all the transport experiments, $600 \mu \mathrm{L}$ samples were removed from the basolateral chamber after 30, 60 and $120 \mathrm{~min}$, and replaced with fresh HBSS. The samples were analyzed in a liquid scintillation counter (1900GA TriCarb; PerkinElmer Life Sciences). The apparent permeability coefficient $\left(\mathrm{P}_{\text {app }}\right)$ was calculated according to the following equation:

$P_{a p p}=\frac{d Q}{d t} \times \frac{1}{A \times C_{d o n o r}}$

where $Q$ is the $\left[{ }^{14} \mathrm{C}\right]$ mannitol appearing in the acceptor compartment as a function of time $(\mathrm{t}), \mathrm{A}$ is the surface area of the Transwell membrane $\left(1.12 \mathrm{~cm}^{2}\right)$, and $\mathrm{C}_{\text {donor }}$ is the initial $\left[{ }^{14} \mathrm{C}\right.$ ] mannitol in the donor compartment. $\mathrm{P}_{\text {app }}$ values below $0.5 \times 10^{-6} \mathrm{~cm} / \mathrm{s}$ were defined as reflecting confluent monolayers, whereas values between 0.5 and $1.0 \times 10^{-6} \mathrm{~cm} / \mathrm{s}$ or $>1.0 \times 10^{-6} \mathrm{~cm} / \mathrm{s}$ reflected intermediate and high incompatibility, respectively.

\section{Progesterone Permeability}

Progesterone was used to investigate the impact of mucin as a diffusion barrier to lipophilic compounds. Similarly to mannitol, transport studies with progesterone $\left(\mathrm{C}_{\text {donor }} 25 \mu \mathrm{M}\right)$ were performed in the absence and presence of mucin. Samples were analyzed using a HPLC (Agilent Technologies 1290 Infinity) with a Zorbrax Eclipse XDB-C18 column $(4.6 \times$ $100 \mathrm{~mm}$ ) (Agilent Technologies). The injection volume was $20 \mu \mathrm{L}$. The mobile phase consisted of acetonitrile:sodium 
acetate buffer ( $\mathrm{pH} 5)$ at 85:15 (v/v) and was used at an isocratic flow rate of $1 \mathrm{~mL} / \mathrm{min}$. The retention time of progesterone was $1.98 \mathrm{~min}$.

\section{Statistical Analysis}

Data are presented as mean values with standard deviation $(n=3)$. Statistical analysis was performed using one-way ANOVA followed by a Dunnett's test. $P$-values of less than 0.05 were considered statistically significant.

\section{RESULTS}

\section{Controls}

The assessment of the digestion medium on the monolayer showed that it was compatible with the Caco-2 model as it showed sufficiently low $\mathrm{P}_{\text {app }}$ values for mannitol $(<0.5 \times$ $\left.10^{-6} \mathrm{~cm} / \mathrm{s}\right)$. In addition, $\mathrm{P}_{\text {app }}$ values were similar to values obtained during incubation with HBSS (pH 6.5; Fig. S2) during an incubation of $2 \mathrm{~h}$. The application of a protective mucin layer, either in a low or high concentration, did not considerably affect the permeability of mannitol (a hydrophilic model compound) or progesterone (a lipophilic model compound), showing that mucin could be used as protective barrier without compromising permeation (Fig. S3).

\section{Excipients}

Caco-2 cells were exposed to the single excipients used in the LBFs for $2 \mathrm{~h}$ (Fig. 1). Triglycerides were compatible with Caco-2 cells at all concentrations tested. The mixed glycerides showed a concentration-dependent incompatibility. Maisine 35-1 (mono-, di- and tri- LC glycerides) damaged the monolayer at a concentration of $1.25 \%(w / v)$ and Capmul MCM (mono-, di- and tri- MC glycerides) was incompatible already at low concentrations $\geq 0.625 \%$ (w/v). Cremophor EL and Carbitol showed intermediate tolerability at all concentrations whereas Tween 85 and PEG400 were compatible (Fig. 1).

\section{Lipid-Based Formulations}

Type II-LG and IV formulations were tolerated by the cells upon immediate exposure in relevant concentrations of $2.5 \%$ (w/v), i.e., no mucin was required to protect the monolayers (Fig. 2). For type IIIB-LC LBF $\mathrm{P}_{\text {app }}$ values indicated intermediate tolerability. The cell monolayer integrity was maintained by adding a low concentration of mucin $(100 \mu \mathrm{L}$ of $50 \mathrm{mg} /$ $\mathrm{mL}$ ) together with the type I-LC formulation whereas a higher concentration $(200 \mu \mathrm{L}$ of $150 \mathrm{mg} / \mathrm{mL})$ was required to protect against the IIIA-LC. MC-LBFs were generally not compatible with Caco-2 monolayers (Fig. 2). However, the high mucin

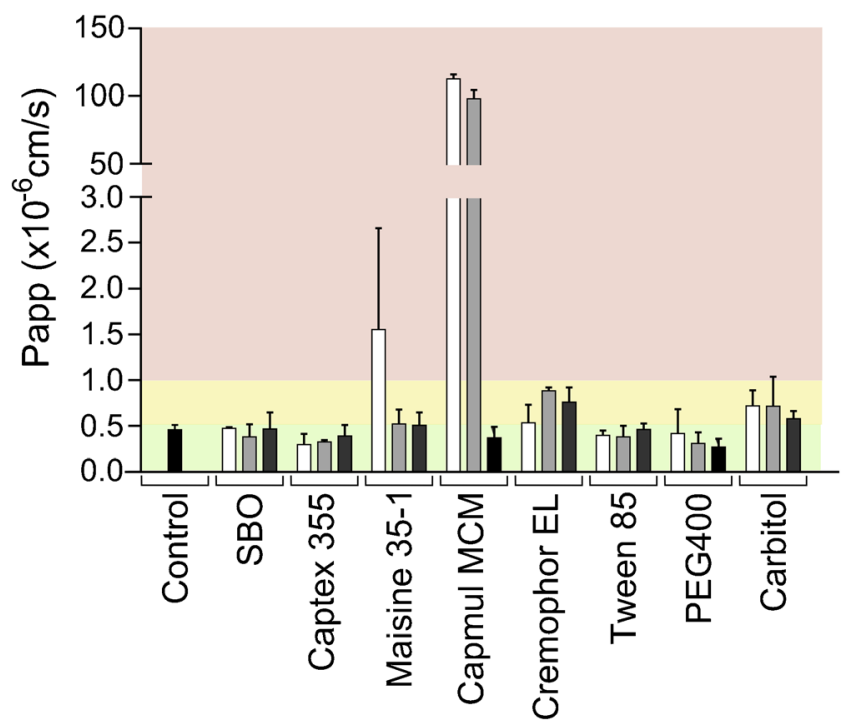

Fig. I Effect of excipients on apical to basolateral transport of mannitol across Caco-2 monolayers. Bars represent average $P_{\text {app }}$ values $\pm S D(n=3)$. The black bar represent the control i.e. digestion medium. The white, light gray and, dark gray bars indicate excipient concentrations of $1.25,0.625$, and $0.125 \%(w / N)$, respectively. Red, yellow and green regions represent conditions that were not, intermediately and well tolerated.

concentration $(200 \mu \mathrm{L}$ of $150 \mathrm{mg} / \mathrm{mL}$ ) protected the monolayers against the damaging effects of the II-MC and IIIB-MC formulations.

\section{Enzymes}

The standardized in vitro method to assess lipolysis of LBFs, suggested by the LFCS consortium, uses an extract from porcine pancreas (17). However, this concentration of pancreatic extract (Table III) disrupted Caco-2 monolayers, even in the

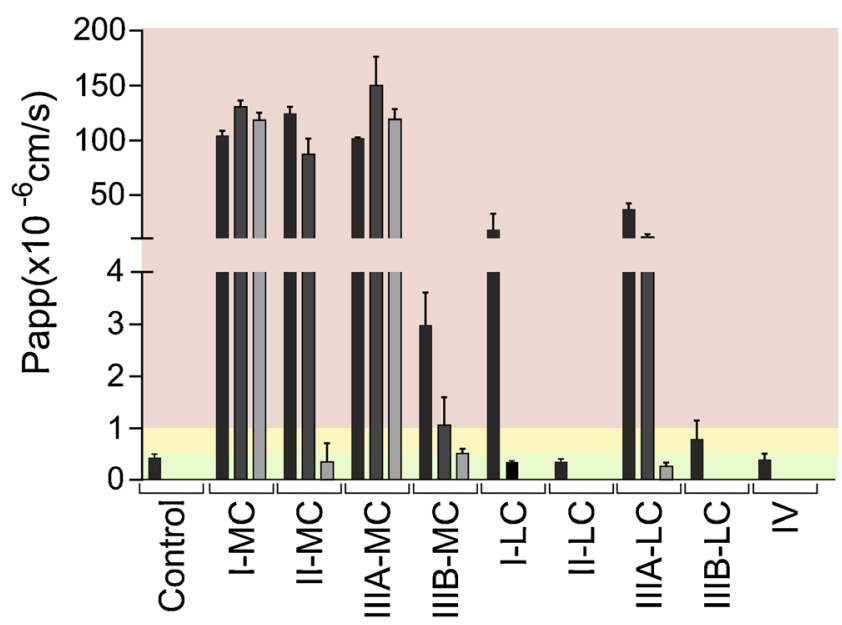

Fig. 2 Effect of undigested LBFs on apical to basolateral transport of mannitol across Caco- 2 monolayers. Bars represent average $P_{\text {app }}$ values $\pm S D(n=3)$. The black, dark gray, and light gray bars indicate the presence of no mucin, $100 \mu \mathrm{L}$ of $50 \mathrm{mg} / \mathrm{mL}$ mucin, and $200 \mu \mathrm{L}$ of $150 \mathrm{mg} / \mathrm{mL}$ mucin, respectively. Red, yellow and green regions represent conditions that were not, intermediately and well tolerated. The control was digestion medium. 
presence of mucin (Fig. 3). Therefore, the use of recombinant lipase immobilized on polymeric beads (Novozym $\left.{ }^{\circledR} 435\right)$ was evaluated for the digestion of LBFs. A considerable release of FFA was observed during the digestion of all LBFs with 125 PLU/mL immobilized lipase (Fig. 4). Immediate exposure to this concentration of the enzyme was tolerated well by the cells (Fig. 3).

\section{Digestion Products}

Caco-2 cells were exposed to caprylic and oleic acid representing digestion products released from $\mathrm{MC}$ - and LC-formulations, respectively. Mucin protected the cells against caprylic acid in a concentration-dependent manner. The highest concentration of mucin was required to shield the cells completely from its damaging effects. For the oleic acid, the lower concentration of mucin was already sufficient to protect monolayers against disruptive effects (Fig. 5).

\section{Digested Lipid-Based Formulations}

LBFs were digested for $60 \mathrm{~min}$ to obtain media containing the excipients, immobilized lipase, and digestion products (Fig. 4). The MC formulations proved to be less damaging upon digestion than when administered in their undigested form (Figs. 2 and 6). Only intermediate monolayer damage was observed for the digested type II-MC and the IIIB-MC formulations. In contrast, all LC formulations and the type IV formulation exerted disruptive effects upon digestion whereas damaging effects were only observed for highly concentrated, undigested I-LC and IIIA-LC formulations (Figs. 2 and 6). Only the high

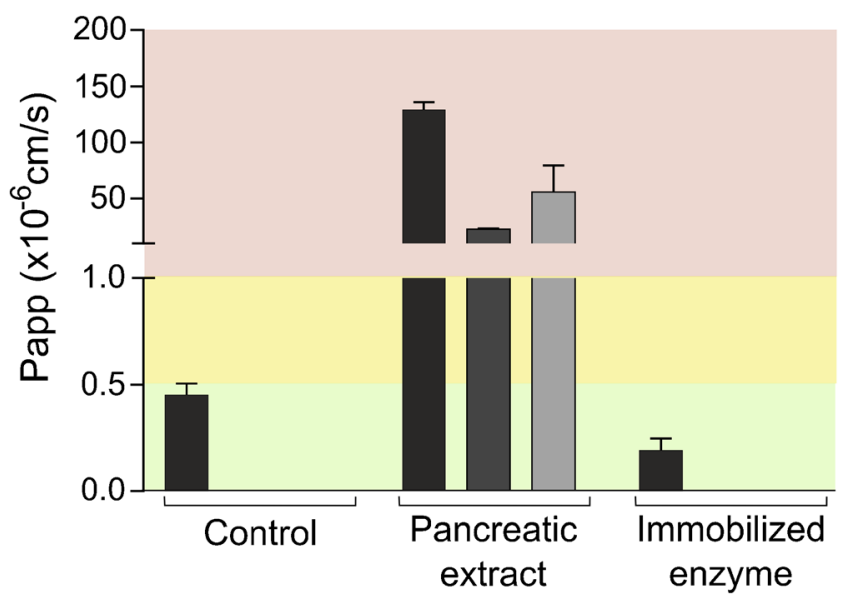

Fig. 3 Effect of enzymes on apical to basolateral transport of mannitol across Caco-2 monolayers. Bars represent average $P_{\text {app }}$ values $\pm S D(n=3)$. The black, dark gray, and light gray bars indicate the presence of no mucin, $100 \mu \mathrm{L}$ of $50 \mathrm{mg} / \mathrm{mL}$ mucin, and $200 \mu \mathrm{L}$ of $150 \mathrm{mg} / \mathrm{mL}$ mucin, respectively. Red, yellow and green regions represent conditions that were not, intermediately and well tolerated. The control was digestion medium. mucin concentration $(200 \mu \mathrm{L}$ of $150 \mathrm{mg} / \mathrm{mL})$ was evaluated for protection of digested $\mathrm{LBF}_{\mathrm{S}}$ since the low concentration $(100 \mu \mathrm{L}$ of $50 \mathrm{mg} / \mathrm{mL}$ ) has shown incomplete protection in previous experiments with single components of LBFs. In the presence of high mucin concentrations, all digested formulations were compatible with the Caco-2 cells (Fig. 6).

\section{DISCUSSION}

Recent studies have identified the absence of an absorption compartment in the current in vitro lipolysis setup as a major reason for the poor prediction of the in vivo performance of LBFs $(3,6,7)$. Therefore, the present study evaluated the compatibility between Caco-2 monolayers - the gold standard for intestinal absorption in vitro studies (11) — and components present during digestion studies. A number of excipients, LBFs, and digestion products, were shown to be tolerated by the cells at concentration levels relevant for evaluation of LBF performance. The pancreatic enzyme commonly used in standard lipolysis was found to be incompatible under all conditions tested, but immobilized lipase was endured by the Caco-2 monolayers at a concentration able to digest LBFs representing all classes of the LFCS (Figs. 3 and 4, respectively). Of particular interest is the fact that LBF concentrations used in digestion experiments could be applied without the need for dilution. Cells tolerated these concentrations during $2 \mathrm{~h}$ of incubation, which is significantly longer than a typical lipolysis experiment (30-60 min) $(6,17)$. This opens up the possibility of coupling the lipolysis setup to an absorption chamber consisting of Caco-2 cells to perform lipolysis and absorption studies simultaneously.

$\mathrm{P}_{\text {app }}$ and TEER measurements have been used extensively to evaluate monolayer integrity of Caco-2 cells (1 1, 12, 19,20). These parameters correlated well in this study (i.e. a decrease in TEER corresponded to an increase in $\mathrm{P}_{\text {app }}$ of mannitol, Fig. S3 and S4). However, TEER measurements must be interpreted with caution. Variability in TEER can be introduced by fluctuations in temperature, medium formulation, passage number, and even the positioning of the electrodes. The most widely used system for measuring TEER consists of a pair of electrodes (known as chopsticks) and the electrodes only determine TEER locally (21). We therefore use the TEER measurements to identify cell monolayers that are suitable for transport studies, whereas we use a permeation marker such as mannitol or lucifer yellow to study monolayer integrity (12). When incubations resulted in mannitol $\mathrm{P}_{\text {app }}$ values below $0.5 \times 10^{-6} \mathrm{~cm} / \mathrm{s}$, components were considered compatible with Caco-2 cells. However, some conditions resulted in $\mathrm{P}_{\text {app }}$ values that were below values obtained in the control condition (only digestion medium). A possible explanation is that some excipients 
Fig. 4 Apparent titration of FFA release during in vitro lipolysis $(n=$ I). (a) MC LBFs (b) LC-LBFs and IV-LBF.
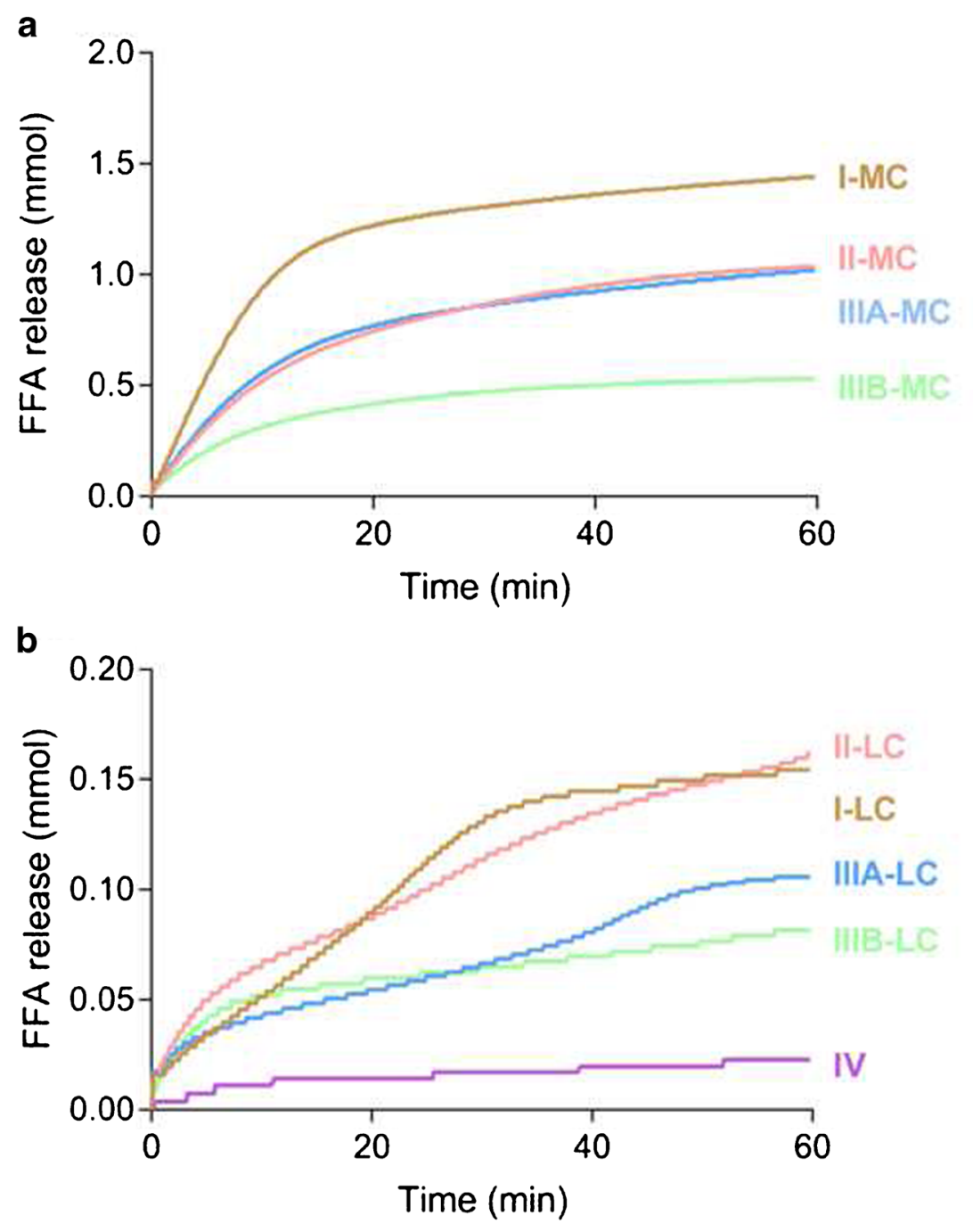

including lipids can induce structural changes in the mucin, possibly resulting in decreased permeation (22).Vors et al. previously performed lipolysis experiments on emulsions followed by incubations on differentiated Caco-2 cells (13). However, to maintain the monolayer integrity they had to significantly dilute the digestion medium $(1: 20)$. Bu et al. exposed cells to $0.5 \%(v / \mathrm{v}) \mathrm{LBF}$ and concluded that compatibility was influenced by the maturity of monolayers; differentiation was required for 21 days to optimize the survival rate $(12,14)$. Both studies used LBF concentrations that were much lower than concentrations used in in vitro lipolysis experiments. Recently, Sadhukha et al. demonstrated the compatibility of Caco-2 cells with a selection of undigested LC formulations at concentrations relevant for in vitro lipolysis experiments. In agreement with the findings in the current study, they found that digested LC formulations showed significantly more incompatibility, i.e., lower TEER- and higher $\mathrm{P}_{\text {app }}$ values, than the corresponding undigested LBFs (15).
Cremophor EL and Tween 85 have previously been applied on differentiated Caco-2 cells as single excipients. In those experiments, a $2 \mathrm{~h}$ incubation of Cremophor EL $(0.5 \%(\mathrm{v} / \mathrm{v}))$ resulted in a slight decrease in cell viability according to a MTT test, but viability was still around $80 \%$ (14). Acceptable tolerance upon exposure to the Cremophor EL was also observed in our study, even after adding relatively high concentrations $(0.625 \%-1.25 \%(w / v)$, Fig. 1). Up to $5 \%$ (w/v) Tween 85 was previously shown to be tolerated well by Caco-2 cells (23). This corroborates our observations as no damaging effects were observed at concentrations between 0.125 and $1.25 \%(\mathrm{w} / \mathrm{v})$ (Fig. 1).

We demonstrated that the compatibility of LBFs and Caco-2 cells was highly influenced by formulation composition. A connection was observed between single excipient incompatibility and the effect of undigested LBFs on the cells. Undigested LBFs containing Capmul MCM, the excipient that caused severe integrity loss of the monolayers, were clearly more disruptive to the cells than other formulations 


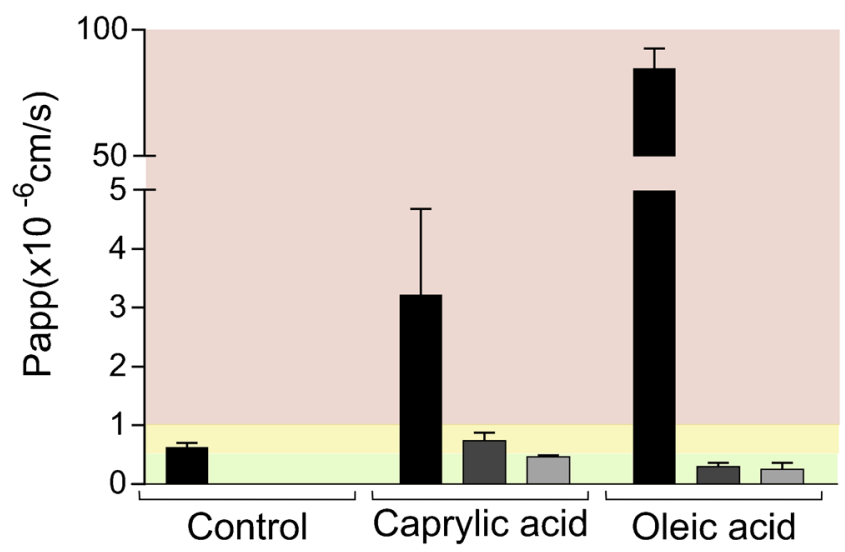

Fig. 5 Effect of caprylic acid (87 mM) and oleic acid (37.5 mM) on apical to basolateral transport of mannitol across Caco-2 monolayers. Bars represent average $P_{\text {app }}$ values $\pm S D(n=3)$. The black, dark gray, and light gray bars indicate the presence of no mucin, I $00 \mu \mathrm{L}$ of $50 \mathrm{mg} / \mathrm{mL}$ mucin, and $200 \mu \mathrm{L}$ of $150 \mathrm{mg} / \mathrm{mL}$ mucin, respectively. Red, yellow and green regions represent conditions that were not, intermediately and well tolerated. The control was digestion medium.

(Table II and Fig. 2). Moreover, cells exposed to the IIIB-MC formulation, which contained the lowest fraction of Capmul MCM, performed better than the cells exposed to other MCLBFs containing higher concentrations of this excipient. This is in agreement with previous data from $\mathrm{Bu}$ et al. who detected a decrease in toxicity when formulations contained higher amounts of Captex 355 in favor of Capmul MCM. In addition, they observed that formulations consisting of mixtures of mono-, di-, triglycerides and surfactants were better tolerated by monolayers than the single lipids or surfactants (14).

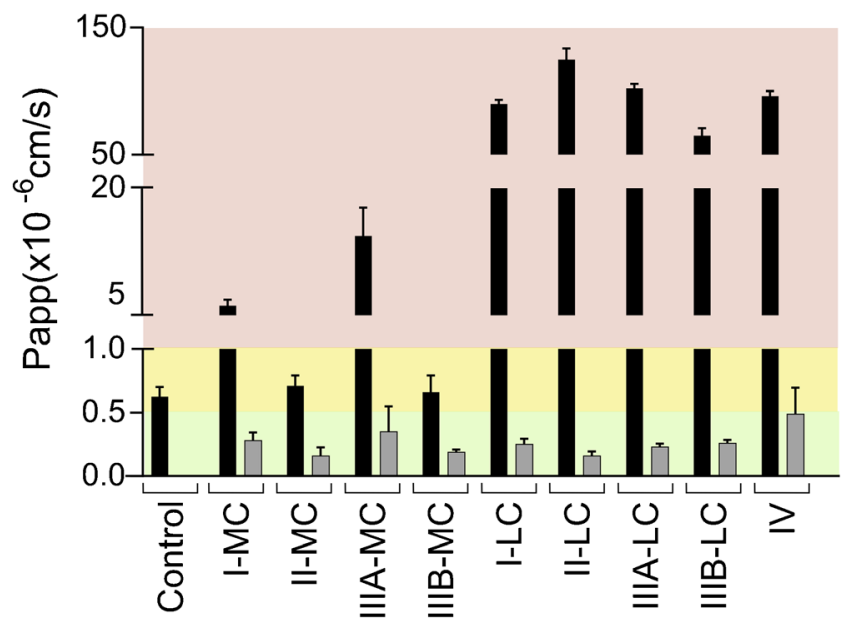

Fig. 6 Effect of digested LBFs on apical to basolateral transport of mannitol across Caco- 2 monolayers. Bars represent average $P_{\text {app }}$ values $\pm \operatorname{SD}(n=3)$. The black and light gray bars indicate the presence of no mucin and $200 \mu \mathrm{L}$ of $150 \mathrm{mg} / \mathrm{mL}$ mucin, respectively. Only the high mucin concentration was evaluated for protection of digested LBFs since the low concentration ( $100 \mu \mathrm{L}$ of $50 \mathrm{mg} / \mathrm{mL}$ ) has shown incomplete protection in previous experiments with single components of LBFs. Red, yellow and green regions represent conditions that were not, intermediately and well tolerated. The control was digestion medium.
A clear connection between Caco-2 compatibility and the digestion process was detected. Overall, undigested MC formulations appeared to be more damaging to the cells than their digested counterparts (Figs. 2 and 6, respectively). Given that the critical micelle concentration (CMC) decreases with increasing chain length of the hydrophobic tails (25), the free concentrations of glycerides in dispersions of undigested MC-LBFs is relatively high. These free MC glycerides may insert into, and disrupt, membranes leading to lipid-induced rupture of the cells $(14,25)$. Upon digestion, cells will be exposed to MC digestion products (MC FFA). Absorption enhancing effects of MC FFAs have been shown to occur in the vicinity of the CMC (19). Therefore, caprylic acid exhibited limited effects on membrane integrity when a much lower concentration $(87 \mathrm{mM}$ ) than the CMC (225 mM) was applied (Fig. 6) (19,25).This may also provide an explanation for the mild membrane interactions observed for the digested MCLBFs (Fig. 6), which when digested contained between 8.8 and $24.0 \mathrm{mM}$ of ionizable FFA. On the contrary, components present in undigested dispersed LC-LBF will form micelles at relatively low concentrations resulting in limited exposure of glycerides to the Caco-2 monolayers. However, oleic acid (37.5 mM) as well as digested LC-LBFs severely damaged Caco-2 monolayers (Figs. 5 and 6, respectively). Upon digestion, released LC FFAs will be incorporated into the cell membrane and destabilize its lamellar phase through decreased transition temperature and the formation of inverted hexagonal phases (26). Oleic acid in particular, has been shown to affect membranes at mole fractions down to 0.025. Assuming (i) that the surface area occupied per phospholipid is about $64 \AA^{2}$ (value for phosphatidylcholine) and (ii) the entire apical surface of the culture insert is covered by the monolayer (i.e. no paracellular transport route), only $0.005 \%$ of the LC FFA explored here would have to be inserted to exert a harmful effect $(27,28)$.

Mucus, secreted by goblet cells, provides a protective barrier towards harmful endogenous and foreign substances in viwo. However, as Caco-2 cells originate from a colon cancer cell line, they do not always replicate the physiology of in vivo tissue and, for example, lack a mucus layer (29). Caco-2 cells could therefore be co-cultured with human mucus-producing cells to establish a mucus layer containing glycoproteins that mimic the protective barrier in the human gut (30). However, these co-cultures are relatively difficult to maintain and mucus layers can be easily removed during washing steps. Therefore, monolayers were in this study shielded against harmful effects by applying a protective porcine derived mucin layer on top of the cell barrier. This strategy has been used previously by Wuyts et al. who applied a barrier of mucin onto Caco-2 cells to protect them against fasted state human intestinal fluids (20). The concentration they used in their study was insufficient to completely protect the cells against some of the damaging effects, and so a larger amount of mucin was applied in 
this study ( $200 \mu \mathrm{L}$ of $150 \mathrm{mg} / \mathrm{mL}$ mucin). Mucin has previously been found to significantly obstruct the absorption of lipophilic drugs in co-cultures of Caco-2 cells with mucinproducing HT29-MTX cells (31). Indeed, $\mathrm{P}_{\text {app }}$ of the lipophilic model compound progesterone was reduced in the presence of the low concentration of mucin but no statistical significant difference in $\mathrm{P}_{\text {app }}$ value was observed between the low and high mucin concentration. In both conditions, the transport was still considerable and the diffusion through the mucin layer was high (Fig. S5). $\mathrm{P}_{\text {app }}$ values obtained after the addition of mucin onto the Caco-2 cells while studying permeation of a selection of compounds (including lipophilic compounds) strongly correlated with $\mathrm{P}_{\text {app }}$ values obtained in the absence of mucin and with fractions absorbed in humans (20). Therefore, we do not expect the mucin to limit the usefulness of Caco-2 cells in combination with mucin in an absorption chamber for drug permeation studies.

Despite the protective barrier, Caco-2 cells were not able to tolerate the pancreatic extract. An alternative could therefore be to use artificial membranes to evaluate absorption of compounds during digestion of LBFs with the extract. For example, the biomimetic barrier Permeapad has been shown to maintain its permeation properties during the digestion of a type IIIA-LC LBF with the extract (32). However, we initially targeted the development of a cell-based model since Caco-2 cells enable both active and passive transport mechanisms to be explored (12). Although compounds formulated in LBFs typically cross the intestinal barrier through passive diffusion, other compounds, including bile salts and FFA, are substrates of transporters $(33,34)$. Transporter-mediated uptake of these components changes the composition of the digestion medium and consequently its solvation capacity. It is therefore to be expected that cell-based systems more accurately capture the dynamics of the solubilizing intestinal lipoidal structures than e.g., artificial membranes.

In order to use Caco-2 cells during digestion studies, we found that the lipids need to be digested with immobilized lipase (Novozym $\left.{ }^{\circledR} 435\right)$ instead of pancreatic extract. Novozym ${ }^{\circledR} 435$ is a recombinant lipase B originating from Candida Antarctica that is immobilized on a macroporous polyacrylate resin. A modified in vitro digestion model employing this enzyme has been developed previously, showing that a similar extent of digestion could be obtained for the digestion of Captex 355 and Tricaprylin provided that the digestion lasts long enough. The activity of the immobilized lipase was shown to be independent of buffer or $\mathrm{pH}$, enabling its use in protocols mimicking lipid digestion in different segments of the gastrointestinal tract (35). Other advantages are that immobilized lipase (i) enables easy separation from the digestion medium (ii) is reusable and, (iii) shows increased thermal stability. The activity of immobilized lipase is however slightly different to that of pancreatic extract (Fig. S1). This difference may be due to the specificity and affinity of the enzymes. The immobilized lipase consists of only one kind of lipase, whereas pancreatic extract contains a mixture of enzymes including phospholipase A2, colipase, and pancreatic lipase-related protein (35). In addition, access of the active site of immobilized lipase to triglycerides might be limited. Due to their low solubility in the aqueous phase triglycerides will mainly reside in the oil droplets and digestion needs to occur at the droplet interface. As immobilized lipase is confined to polymeric beads, it is likely that steric hindrance slows down digestion by this enzyme while pancreatic lipase that is dispersed freely in the digestion medium has easier access to the droplet interface. In contrast to human and porcine pancreatic lipase, the immobilized lipase does not display interfacial activation; i.e. a conformational change in the presence of a hydrophobic surface, resulting in exposure of the active site to the solvent. However, the active site is composed of the same catalytic triad consisting of serine, aspartic acid and histidine (36). As pancreatic extract in a concentration of $90 \mathrm{USPU} / \mathrm{mL}$ was shown to be compatible with Caco-2 cells in the presence of high mucin concentrations (Fig. S6A), the concomitant effects of $125 \mathrm{PLU} / \mathrm{mL}$ immobilized lipase and $90 \mathrm{USPU} / \mathrm{mL}$ of pancreatic extract on the digestion of IIIB-MC was evaluated (Fig. S6B). Unfortunately, combinations of the enzymes were incompatible with the cells (Fig. S6A) and had only limited effects on the extent of digestion (Fig. S6B).

Several studies have been undertaken to increase the physiological relevance of the in vitro lipolysis setup. For instance, as lipolysis is initiated in the stomach, a gastric lipolysis phase has been added (37). To capture the dynamics of the intestinal processes occurring after administration of a lipid-based drug delivery system an absorption sink needs to be added. As pancreatic extract is not compatible with Caco-2 cells (Fig. 3) we suggest to use immobilized lipase in the development of such a digestion model including absorption.

In the present study, pre- and post-digestion conditions tolerated by Caco-2 cells were identified in spite of the studies being designed as a 'worst-case' scenario with high concentration of natural and digested excipients being in contact with the cells for as long as $2 \mathrm{~h}$. Hence, Caco-2 cell monolayers seem as a promising approach to study absorption simultaneously with lipolysis during performance testing of LBFs.

\section{CONCLUSION}

We here demonstrated that Caco-2 monolayers are a promising tool in the development of a new method to couple in vitro lipolysis to an absorption compartment. The pancreatic extract typically used during lipolysis was damaging for the Caco-2 cell monolayers and so an immobilized lipase was used instead; it successfully digested the LBFs and was tolerated by 
the cell monolayers. Caco-2 cells, in combination with a protective mucin barrier, withstood all the undigested and digested LBFs explored herein except the undigested type IMC and IIIA-MC formulations. These studies were performed in a 'worst case' scenario where the Caco-2 cells were exposed to high concentrations of all components for two hours. Digestion studies typically run for 30-60 min during which the condition is dynamic and we therefore expect that the Caco-2 cell model will perform even better under such circumstances.

\section{ACKNOWLEDGMENTS AND DISCLOSURES}

This work has received support from the European Research Council Grant 638965 and the Swedish Research Council Grant 2014-3309.

Open Access This article is distributed under the terms of the Creative Commons Attribution 4.0 International License (http://creativecommons.org/licenses/by/4.0/), which permits unrestricted use, distribution, and reproduction in any medium, provided you give appropriate credit to the original author(s) and the source, provide a link to the Creative Commons license, and indicate if changes were made.

\section{REFERENCES}

1. Carrière F. Impact of gastrointestinal lipolysis on oral lipid-based formulations and bioavailability of lipophilic drugs. Biochimie. 2016;125:297-305.

2. Pouton CW. Formulation of poorly water-soluble drugs for oral administration: physicochemical and physiological issues and the lipid formulation classification system. Eur J Pharm Sci. 2006;29(3-4):278-87.

3. Feeney OM, Crum MF, McEvoy CL, Trevaskis NL, Williams HD, Pouton CW, et al. 50years of oral lipid-based formulations: provenance, progress and future perspectives. Adv Drug Deliv Rev. 2016;101:167-94.

4. Kollipara S, Gandhi RK. Pharmacokinetic aspects and in vitro-in vivo correlation potential for lipid-based formulations. Acta Pharm Sin B. 2014;4(5):333-49.

5. Kostewicz ES, Abrahamsson B, Brewster M, Brouwers J, Butler J, Carlert $\mathrm{S}$, et al. In vitro models for the prediction of in vivo performance of oral dosage forms. Eur J Pharm Sci. 2014;57:342-66.

6. Thomas N, Richter K, Pedersen TB, Holm R, Müllertz A, Rades T. In vitro lipolysis data does not adequately predict the in vivo performance of lipid-based drug delivery systems containing fenofibrate. AAPS J. 2014;16(3):539-49.

7. Gautschi N, Bergström CAS, Kuentz M. Rapid determination of drug solubilization versus supersaturation in natural and digested lipids. Int J Pharm. 2016;513(1-2):164-74.

8. Stillhart C, Imanidis G, Griffin BT, Kuentz M. Biopharmaceutical modeling of drug supersaturation during lipid-based formulation digestion considering an absorption sink. Pharm Res. 2014;31(12): 3426-44.

9. Dahan A, Hoffman A. The effect of different lipid based formulations on the oral absorption of lipophilic drugs: the ability of in vitro lipolysis and consecutive ex vivo intestinal permeability data to predict in vivo bioavailability in rats. Eur J Pharm Biopharm. 2007;67(1):96-105.

10. Crum MF, Trevaskis NL, Williams HD, Pouton CW, Porter GJH. A new in vitro lipid digestion - in vivo absorption model to evaluate the mechanisms of drug absorption from lipid-based formulations. Pharm Res. 2016;33(4):970-82.

11. Sambuy Y, De Angelis I, Ranaldi G, Scarino ML, Stammati A, Zucco F. The Caco-2 cell line as a model of the intestinal barrier: influence of cell and culture-related factors on Caco-2 cell functional characteristics. Cell Biol Toxicol. 2005 Jan;21(1):1-26.

12. Hubatsch I, Ragnarsson EGE, Artursson P. Determination of drug permeability and prediction of drug absorption in Caco-2 monolayers. Nat Protoc. 2007;2(9):2111-9.

13. Vors C, Capolino P, Guérin C, Meugnier E, Pesenti S, Chauvin M$\mathrm{A}$, et al. Coupling in vitro gastrointestinal lipolysis and Caco-2 cell cultures for testing the absorption of different food emulsions. Food Funct. 2012;3(5):537.

14. Bu P, Narayanan S, Dalrymple D, Cheng X, Serajuddin ATM. Cytotoxicity assessment of lipid-based self-emulsifying drug delivery system with Caco-2 cell model: Cremophor EL as the surfactant. Eur J Pharm Sci. 2016;91:162-71.

15. Sadhukha T, Layek B, Prabha S. Incorporation of lipolysis in monolayer permeability studies of lipid-based oral drug delivery systems. Drug Deliv Transl Res. 2017.

16. Pouton CW, Porter CJH. Formulation of lipid-based delivery systems for oral administration: materials, methods and strategies. Adv Drug Deliv Rev. 2008;60(6):625-37.

17. Williams HD, Sassene P, Kleberg K, Bakala-N'Goma J-C, Calderone M, Jannin $\mathrm{V}$, et al. Toward the establishment of standardized in vitro tests for lipid-based formulations, part 1: method parameterization and comparison of in vitro digestion profiles across a range of representative formulations. J Pharm Sci. 2012;101(9):3360-80.

18. Alskär LC, Porter GJH, Bergström CAS. Tools for early prediction of drug loading in lipid-based formulations. Mol Pharm. 2016;13(1):251-61.

19. Lindmark T, Nikkilä T, Artursson P. Mechanisms of absorption enhancement by medium chain fatty acids in intestinal epithelial Caco2 cell monolayers. J Pharmacol Exp Ther. 1995 Nov;275(2):958-64.

20. Wuyts B, Riethorst D, Brouwers J, Tack J, Annaert P, Augustijns P. Evaluation of fasted state human intestinal fluid as apical solvent system in the Caco-2 absorption model and comparison with FaSSIF. Eur J Pharm Sci. 2015;67:126-35.

21. Srinivasan B, Kolli AR, Esch MB, Abaci HE, Shuler ML, Hickman JJ. TEER measurement techniques for in vitro barrier model systems. J Lab Autom. 2015;20(2):107-26.

22. Yildiz HM, Speciner L, Ozdemir C, Cohen DE, Carrier RL. Foodassociated stimuli enhance barrier properties of gastrointestinal mucus. Biomaterials. 2015 Jun;54:1-8.

23. Dimitrijevic D, Shaw AJ, Florence AT. Effects of some non-ionic surfactants on transepithelial permeability in Caco-2 cells. J Pharm Pharmacol. 2000;52(2):157-62.

24. James-Smith MA, Shekhawat D, Cheung S, Moudgil BM, Shah DO. Effect of chain length on binding of fatty acids to Pluronics in microemulsions. Colloids Surf B Biointerfaces. 2008 Mar 15;62(1): $5-10$.

25. Schreier S, Malheiros SVP, de Paula E. Surface active drugs: selfassociation and interaction with membranes and surfactants. Physicochemical and biological aspects. Biochim Biophys Acta Biomembr. 2000;1508(1-2):210-34.

26. Ibarguren M, López DJ, Escribá PV. The effect of natural and synthetic fatty acids on membrane structure, microdomain organization, cellular functions and human health. Biochim Biophys Acta Biomembr. 2014 Jun;1838(6):1518-28.

27. Yeagle P. The membranes of cells. Third. Amsterdam: Elsevier; 2016. 
28. Hoopes MI, Noro MG, Longo ML, Faller R. Bilayer structure and lipid dynamics in a model stratum corneum with oleic acid. J Phys Chem B. 2011 Mar 31;115(12):3164-71.

29. Lundquist P, Artursson P. Oral absorption of peptides and nanoparticles across the human intestine: opportunities, limitations and studies in human tissues. Adv Drug Deliv Rev. 2016;106(Pt B):256-76.

30. Hilgendorf C, Spahn-Langguth H, Regårdh CG, Lipka E, Amidon GL, Langguth P. Caco-2 versus Caco-2/HT29-MTX Co-cultured cell lines: permeabilities via diffusion, inside- and outside-directed carrier-mediated transport. J Pharm Sci. 2000;89(1):63-75.

31. Behrens I, Stenberg P, Artursson P, Kissel T. Transport of lipophilic drug molecules in a new mucus-secreting cell culture model based on HT29-MTX cells. Pharm Res. 2001 Aug; 18(8):1138-45.

32. Bibi HA, Holm R, Bauer-Brandl A. Simultaneous lipolysis/ permeation in vitro model, for the estimation of bioavailability of lipid based drug delivery systems. Eur J Pharm Biopharm. 2017;117:300-7.
33. Anderson CM, Stahl A. SLC27 fatty acid transport proteins. Mol Asp Med. 2013;34(2-3):516-28.

34. Giacomini KM, Huang S-M, Tweedie DJ, Benet LZ, Brouwer KLR, Chu X, et al. Membrane transporters in drug development. Nat Rev Drug Discov. 2010;9(3):215-36.

35. Phan S, Salentinig S, Hawley A, Boyd BJ. Immobilised lipase for in vitro lipolysis experiments. J Pharm Sci. 2015;104(4):1311-8.

36. Blank K, Morfill J, Gumpp H, Gaub HE. Functional expression of Candida antarctica lipase B in Eschericha coli. J Biotechnol. 2006;125(4):474-83.

37. Bakala-N'Goma J-C, Williams HD, Sassene PJ, Kleberg K, Calderone M, Jannin V, et al. Toward the establishment of standardized in vitro tests for lipid-based formulations. 5. Lipolysis of representative formulations by gastric lipase. Pharm Res. 2015;32(4):1279-87. 